\title{
Euclides Roxo e a Proposta Modernizadora do Ensino da Matemática
}

\section{Aparecida Rodrigues Silva Duarte}

\section{Resumo}

Este artigo versa sobre a trajetória profissional de Euclides de Medeiros Guimarães Roxo, professor de matemática do Colégio Pedro II, nas primeiras décadas de século XX. Discorre sobre as propostas pedagógicas para modernização do ensino secundário de matemática no Brasil, que pretendia incorporar, numa só disciplina, a aritmética, a álgebra e a geometria, até então ensinados em separado. Essas modificações foram inspiradas pelo movimento internacional de reforma da matemática, orientado pelo matemático alemão Felix Klein (1849-1925) que se mostrava presente em vários países da Europa. Além disso, Roxo apropriou-se das ideias do matemático e filósofo francês Henri Poincaré (1854-1912), defensor da filosofia intuicionista, para fundamentar suas propostas de renovação do ensino da matemática, adotadas pela reforma Francisco Campos. Para tanto, toma-se como principal fonte de pesquisa documentos que se encontram no Arquivo Pessoal Euclides Roxo (APER), utilizando-se como aporte teórico ensinamentos da história cultural. A reforma Francisco Campos, ao acatar aspectos próprios da corrente filosófica do intuicionismo, que não estavam presentes no ensino tradicional e propostos pelo professor Roxo fez surgir discussões generalizadas na sociedade brasileira, levando a uma reflexão acerca de um modelo até então aceito, sem maiores questionamentos.

Palavras chave: História da educação matemática. Euclides de Medeiros Guimarães Roxo. Modernização do ensino de matemática. Henri Poincaré. 


\title{
Euclides Roxo and the Modernizing Proposal of Teaching Mathematics
}

\author{
Aparecida Rodrigues Silva Duarte
}

\section{Abstract}

This article deals with the professional trajectory of Euclides de Medeiros Guimarães Roxo, professor of mathematics at Colégio Pedro II, in the first decades of the 2oth century. It discusses pedagogical proposals for the modernization of mathematics secondary education in Brazil, which aimed to incorporate, in a single discipline, arithmetic, algebra and geometry, previously taught separately. These changes were inspired by the international Mathematics reform movement, led by Felix Klein (18491925), which was present in several European countries. In addition, Roxo appropriated the ideas of the mathematician and philosopher Henri Poincaré (1854-1912), defender of intuitionist philosophy, to base his proposals for the renewal of mathematics teaching, adopted by the Francisco Campos Reform. For that, the main source of this research is the documents that are found in the Personal Archive Euclides Roxo (APER), using as theoretical contribution teachings of Cultural History. The Francisco Campos Reform, when following the aspects of the philosophical current of Intuitionism, which were not present in the traditional teaching and proposed by Professor Roxo, led to generalized discussions in Brazilian society, leading to a reflection on a model accepted until now, without major questionings.

Keywords: History of mathematics education. Euclides de Medeiros Guimarães Roxo. Modernization of mathematics teaching. Henri Poincaré. 


\section{Introdução}

Este artigo tem como objetivo discorrer como se processaram as práticas educacionais no início do século XX, por meio da reconstrução da trajetória do professor de matemática Euclides de Medeiros Guimarães Roxo, cujas propostas pedagógicas eram condizentes com aquelas apregoadas pelo primeiro Movimento Internacional de Modernização do Ensino da Matemática e foram acatadas nas reformas ocorridas no Colégio Pedro II em 1929 e na reforma Francisco Campos.

Roxo destacou-se por praticar uma intermediação entre o primário e o secundário, propondo uma mudança de concepção, com a introdução do aspecto intuitivo no secundário. Uma preocupação básica que se afigurava era como trazer o intuitivo para esse grau de ensino. Euclides Roxo viu nas ideias pedagógicas do matemático e filósofo Henri Poincaré (1854-1912) - principal referência tomada por Roxo, no âmbito da filosofia da matemática - algumas das respostas para essa questão.

Assim como Poincaré, as ideias pedagógicas para o ensino secundário, sustentadas pelo matemático Felix Klein (1849-1925), também foram privilegiadas por Euclides Roxo, vindo a fazer parte do programa de matemática do ensino secundário durante a década de 1930.

Para a elaboração deste artigo empregou-se como metodologia a pesquisa historiográfica orientada pela história cultural, a qual tem por principal objetivo "identificar o modo como em diferentes lugares e momentos uma determinada realidade social é construída, pensada, dada a ler" (CHARTIER, 1990, p. 16-17). O termo apropriação empregado neste estudo, é também definido por Roger Chartier: “a apropriação, a nosso ver, visa uma história social dos usos e das interpretações, referidas as suas determinações fundamentais e inscritas nas práticas específicas que as produzem” (1991, p.177). O conceito de apropriação assim colocado é central para a história cultural, empregada no sentido de que não se deve privilegiar um conjunto particular de determinações, sejam elas técnicas, econômicas ou demográficas.

Nesse novo enfoque, pretende-se enveredar pelas relações e tensões que constituem essas deliberações, tomando como ponto de partida um tema particular, tal como um acontecimento, importante ou obscuro, um relato de vida, uma rede de práticas específicas. $\mathrm{Na}$ análise de textos, necessário se faz considerar que a leitura é uma prática investida de gestos, espaços, hábitos, sendo utilizada. Chartier sustenta que as formas materiais que revestem um texto também contribuem para dar feição às antecipações do leitor em relação ao texto e para atrair novos públicos e usos inéditos: “O essencial é, portanto, compreender como os mesmos textos - sob formas impressas possivelmente diferentes - podem ser diversamente apreendidos, manipulados e compreendidos" (1991, p.177-182). 
Pinto (2010) destaca a importância dos materiais produzidos na escola para a compreensão das práticas escolares e para a escrita da história de uma disciplina uma vez que se constituem como importante fonte de pesquisa para a escrita da história da matemática escolar. Nesse sentido, a história cultural é uma opção teórica que

[...] considera a produção escolar (livros didáticos, provas, exames, cadernos de alunos e professores) como importante material para a análise do trajeto da educação científico-matemática. Nessa perspectiva, utiliza-se de arquivos escolares e arquivos pessoais de professores como fontes de pesquisa privilegiadas para a escrita da história da educação matemática (DUARTE, 2017, p. 41-32).

Assim, para este estudo, utiliza-se dentre outras fontes, o Arquivo Pessoal de Euclides Roxo, o APER. Trata-se de um acervo que reúne centenas de documentos do professor Euclides Roxo, como: correspondência pessoal, rascunhos de livros didáticos, propostas de programas de ensino, documentos técnico-administrativos, recortes de jornal, trechos traduzidos de livros, exercícios de matemática resolvidos, listas de livros, etc. Estes documentos encontramse de posse do Grupo de Pesquisa de História da Educação Matemática (GHEMAT).

\section{O ensino da matemática na Primeira República}

O Colégio Pedro II, desde sua criação em 1837, era referência de ensino para os demais institutos de curso secundário existentes no país. De acordo com Valente (1999) eram utilizados, no início do século XX, os livros didáticos conhecidos pela sigla F.I.C., significando "Frères de l'Instruction Chrétienne", cuja característica era apresentar cada ramo da matemática de forma independente, além de apresentar grande quantidade de exercícios aos alunos. Desse modo, no Colégio Pedro II lecionava-se a aritmética, a álgebra, a geometria e a trigonometria isoladamente. Cada uma delas consideradas em separado, não havendo preocupação em relacionar esses ramos da matemática (DUARTE, 2002).

Entretanto, no final da década de 20, ocorreram propostas educacionais inovadoras, decorrentes das aspirações da sociedade, cujas atividades industriais estavam em plena expansão, acarretando um crescimento acelerado dos centros urbanos e demandando a criação de estratégias para estimular a formação profissional dos trabalhadores das indústrias. Propostas de modernização da matemática escolar brasileira foram levantadas, com base em um movimento internacional que culminou com a criação, em 1908, do IMUK (Internationale Mathematische Unterrichtskommission), isto é, "Comissão Internacional para o Ensino da Matemática”. Este movimento, presidido por Felix Klein (1849-1925), fazia-se representar em vários países, dentre os quais, França, Alemanha, Inglaterra, Itália e Estados Unidos, em que se procurava discutir e tentar solucionar as dificuldades nessa área.

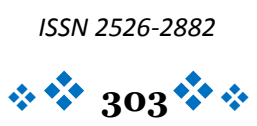


Essas discussões internacionais fizeram surgir novos programas de matemática implementados no Colégio Pedro II, a partir de 1929. O principal responsável por tais mudanças foi o professor Euclides de Medeiros Guimarães Roxo (1890-1950), defensor das propostas pedagógicas sugeridas por Klein. Num artigo do Jornal do Commercio, de 30 de novembro de 1930, sem página, Euclides Roxo defende suas convicções:

Conhecemos muito bem um outro país a que esses conceitos, emitidos para a França em 1900, ainda se aplicam, como uma luva, em 1930. Aqui, como lá, acontece que o ensino secundário não prepara para as escolas superiores e muito menos para a vida, mas para os exames colocados à porta dessas Escolas. Desse modo existe uma verdadeira descontinuidade entre o ensino secundário e o superior, descontinuidade que Klein observava na organização alemã, em virtude da qual o estudante como que recomeça na Universidade o estudo já feito, mas de um ponto de vista inteiramente diferente do que ele encontrou nos ginásios.

Convém destacar que, Euclides de Medeiros Guimarães Roxo nasceu na cidade de Aracaju, Sergipe, em 10 de dezembro de 1890. Após aprovação no exame de admissão, ingressou no Colégio Pedro II tornando-se um dos mais brilhantes alunos dessa escola ${ }^{118}$.

Em 1909, concluiu o curso de bacharelado do Pedro II em seis anos, obtendo distinção grau dez em todas as matérias, conforme atesta o livro de Atas de Exames do Internato Nacional Bernardo de Vasconcelos, (denominação que se dava ao Internato do Colégio Pedro II naquela época). O referido documento encontra-se assinado pelos professores Sílvio Romero, Oiticica de Menezes, João Ribeiro e M. Silva (ATAS doc.1. imagem 173).

Euclides Roxo formou-se em engenharia civil pela Escola Politécnica do Rio de Janeiro em 1916. Iniciou sua vida profissional em 1915, como professor substituto de aritmética do Colégio Pedro II, pelo prazo de três anos. Com o falecimento de Eugênio de Barros Raja Gabaglia, então professor efetivo dessa disciplina, Euclides Roxo assumiu a cátedra em $1^{\circ} \mathrm{de}$ outubro de 1919, em conformidade com artigo 42 do Decreto 11530 e de acordo com documento constante no Arquivo Pessoal Euclides Roxo (APER).

Em 1923, o professor Roxo lançou o livro "Lições de arithmética", dando um passo inovador em relação aos livros da coleção F.I.C. Isto se deu pelo fato de que, Euclides Roxo estava sempre em contato com as novidades ocorridas nos países estrangeiros, por intermédio de seu amigo Paulo Mendes Viana, sócio da Editora Francisco Alves. Em seu livro, fazia uma apropriação do livro de Jules Tannery, "Leçons d’Arithmétique” que, por sua vez, sugeria alterações e mudanças para ensino francês para a disciplina de aritmética (VALENTE, 2004).

118. Após o curso primário era obrigatório o exame de admissão para ingresso no ensino secundário (MACHADO, 2002). 
O livro de aritmética de autoria de Euclides Roxo começou a ser utilizado no Colégio Pedro II, a partir de 1923. Na medida em que este Colégio era modelo para os demais estabelecimentos de ensino existentes no país, o referido livro foi igualmente adotado pelos colégios equiparados ao Pedro II, difundindo-se por todo o Brasil, podendo ser considerado como precursor de suas propostas modernizadoras (VALENTE, 2001).

A partir de 1925, Euclides Roxo assumiu a direção do Externato Pedro II. Nesta posição privilegiada, e sem contar o fato de estar sempre atualizado com os lançamentos de livros de matemática, fizeram com que, em 1927, expusesse sua proposta de renovação do ensino da matemática para a Congregação do Colégio Pedro II, nos moldes das ideias modernizadoras preconizadas pelo movimento internacional de modernização do ensino de matemática.

Na defesa de seus propósitos, passou a difundir os métodos de ensino aprovados na Alemanha e introduzidos por Felix Klein, cuja principal proposta era a de incorporar, numa só disciplina, os ramos da matemática (aritmética, álgebra e geometria) até então ensinados em separado. Outras propostas igualmente inovadoras foram adicionadas, tais como, utilizar a noção de função como eixo de fusão das diversas partes da matemática, permitindo ao estudante a familiarização com os fenômenos científicos e também com situações do cotidiano (VALENTE, 2004).

A reforma, sugerida por Euclides Roxo, foi implantada no Colégio Pedro II, a partir de 1929. Seus pares, que não concordavam com estas modificações, eram minoria naquela ocasião. Assim sendo, Euclides Roxo conseguiu fazer as inovações almejadas, auxiliado por, entre outros, Cecil Thiré e Júlio Cesar de Mello e Souza, lentes do mesmo estabelecimento de ensino. A pretensão era implantar a reforma a partir da primeira série e, gradativamente, serem adotadas nas séries seguintes, de forma a permitir ajustes e promover a participação de professores, com críticas e sugestões no processo que estava sendo colocado em prática. No entanto, com a precipitação dos fatos políticos decorrentes do governo provisório de Vargas, aquelas modificações foram aceleradas, quando da Reforma Francisco Campos.

Com a vitória da Revolução, em novembro de 1930, formou-se o Governo Provisório, tendo Getúlio Vargas como presidente. Vargas tratou de organizar seu ministério, chamando Francisco Campos para a pasta da Educação e Saúde Pública. Vargas incorporou a ideia do nacionalismo, surgindo a centralização do poder, de modo que os estados perderam sua autonomia. Antes de 1930, cada província do Brasil trabalhava de forma autônoma, assim sendo, também ficava a critério de cada uma delas, a administração da parte educacional de seu território (VALENTE, 2001).

Nessa época, como já mencionado, Euclides Roxo exercia o cargo de diretor do Externato Pedro II. Ligado à República Velha e publicamente avesso ao novo poder político ISSN 2526-2882 
vigente, colocou seu cargo à disposição do governo de Vargas, uma vez que tal cargo era de confiança, e, portanto, de livre nomeação pelo presidente da República.

De acordo com seu "curriculum vitae", documento pertencente ao APER e elaborado em dezembro de 1930, Euclides Roxo voltou a assumir importante cargo no Colégio Pedro II, desta vez como diretor do Internato, colocação esta que ocupou até 1937. Ainda em 1931, Francisco Campos, convidou-o para participar da comissão que trataria da reforma do ensino brasileiro, convite este aceito pelo professor Roxo, ficando responsável pela elaboração dos novos programas de matemática do novo governo. Desta forma, as modificações no ensino ocorridas no Colégio Pedro II, acabaram por ser introduzidas em todo o país, quando da reforma Francisco Campos.

A mencionada Reforma, datada de 1931, acolheu as alterações promovidas por Euclides Roxo para o Colégio Pedro II, mas sua implantação deu-se de forma abrupta, isto é, ao invés de um procedimento gradual como fora pensado inicialmente, estas foram incluídas simultaneamente para todas as séries de ensino no país (TAVARES, 2002).

Euclides Roxo foi o primeiro a procurar introduzir no Brasil, os pontos de vistas inseridos no moderno movimento de reforma iniciado na Alemanha por Felix Klein, na conformidade dos dizeres do próprio Roxo, em documento pertencente ao APER, em que relaciona sua vida profissional:

Convidado pelo Ministro Francisco Campos para elaborar os novos programas de matemática baixados com o decreto 19890 de 18 de abril de 1931, redigiu os programas e as instruções pedagógicas para o ensino dessa disciplina de acordo com as modernas tendências e com os pontos de vista que foi o primeiro a preconizar entre nós. Tais instruções se encontram às páginas 51 a 60 do folheto "Organização do Ensino Secundário" junto a uma carta do professor Hahniemam Guimarães, ex-assistente técnico do Ministro na qual o mesmo atesta o que acima foi firmado.

Ainda em 1929, Euclides Roxo lançou seu novo livro, "Mathemática elementar", apresentando a fusão dos conteúdos de aritmética, álgebra e geometria. Apesar de não ter a mesma aceitação que o anterior, "Lições de arithmética", o qual continuava a ser bastante utilizado, o novo didático foi adotado pelo Colégio Pedro II (WERNECK, 2003).

Pelo fato de o Colégio Pedro II ser historicamente referência para todo o Brasil, espalharam-se as ideias modernizadoras por todo país. Ocorreu, também, em consequência, forte resistência por parte de profissionais ligados ao ensino tradicional da matemática.

Os professores Almeida Lisboa, Ramalho Novo, Padre Arlindo Vieira e o Tenente Coronel Sebastião Fontes, foram alguns dos que se manifestaram publicamente contra a reforma de ensino recém-implantada, por considerá-la antipedagógica. O Jornal do 
Commercio foi um dos meios utilizados para a publicação de críticas às renovações empreendidas por Roxo.

Tais críticas provavelmente fizeram com que o professor Euclides Roxo procurasse igualmente, no mesmo jornal, defender a reforma aprovada para o Colégio Pedro II. A partir de 30 de novembro de 1930, começou a expor os motivos que o levaram a se engajar no movimento de renovação do ensino de matemática, baseando-se no que já estava ocorrendo na Europa e Estados Unidos. Esses artigos, intitulados "O ensino da matemática na escola secundária” foram publicados sempre aos domingos, até $1^{\circ}$ de março de 1931.

\section{As ideias pedagógicas de Euclides Roxo}

As proposições de Euclides Roxo defendidas no seu livro "Curso de matemática elementar" e também nos artigos dominicais do Jornal do Commercio, já citados anteriormente, tentavam justificar sua adesão ao movimento internacional de modernização do ensino de matemática, "perante os meios educacionais brasileiros, das últimas modificações introduzidas nos programas de matemática do Colégio Pedro II" (JORNAL DO COMMERCIO, 30 nov. 1930, s/p.).

Seus principais pensamentos, defendidos não só durante esse período, como também na Reforma Francisco Campos e posteriormente na Reforma Gustavo Capanema, diziam respeito a diversos aspectos pedagógicos. Defendia a fusão dos diferentes ramos da matemática, interligando-os em uma única disciplina. Considerava fundamental a introdução do conceito de função, de modo a possibilitar esta conexão entre as diversas partes da matemática (JORNAL DO COMMERCIO, 14 dez. 1930, s/p.).

Os conceitos a serem ensinados deveriam obedecer a uma sequência que facilitasse $o$ aprendizado dos conteúdos da matemática. Assim, necessário seria partir de um conhecimento intuitivo para depois atingir a forma mais abstrata e formal que a matemática adquiriu através dos séculos. Indispensável, portanto, que os professores tivessem uma base sólida em história da matemática.

Desse modo, as ideias do professor Roxo se harmonizam com as recomendações pedagógicas de Henri Poincaré (1854-1912), que considerava o fracasso no ensino da matemática era devido ao fato de que suas teorias eram apresentadas sem que se justificassem as razões de sua escolha, sem mostrarem as tentativas e os esforços para sua elaboração, ocorridos ao longo da história. Portanto, os estudantes apresentavam dificuldades em compreender teorias quando estas eram exibidas de forma definitiva, formal, apartada de seu desenvolvimento e significado, posto que estas assumiam um aspecto artificial.

Os professores, ao esquecerem as raízes históricas da matemática, não observavam o como e o porquê de suas questões propostas, apresentando suas teorias de modo ISSN 2526-2882 
demasiadamente formal. Para Poincaré, recorrer à história era mais uma concessão necessária que o professor deveria proporcionar ao aluno, respeitando seu processo de maturação psicológica (BRUTER, 1996).

Para Euclides Roxo, a escola deveria respeitar a lógica própria de cada indivíduo, defendendo que a lógica sistemática constituir-se-ia em ponto final e não ponto de partida: "A intuição forma a base do conhecimento e, a princípio, só lentamente se penetra na consciência da lógica”. Buscava um ensino balanceado, unindo intuição e dedução. O ensino intuitivo seria utilizado nas séries iniciais do secundário, com o objetivo de preparar o aluno para as séries finais. Quando este já tivesse maturidade suficiente, ser-lhe-ia então, apresentado o método dedutivo (JORNAL DO COMMERCIO, 14 dez. 1930, s/p.).

Nota-se também nesse aspecto, concordância com os pensamentos de Poincaré, quando este argumentava que se deveria esperar que o aluno estivesse familiarizado com o raciocínio matemático de modo que, quando seu raciocínio estivesse amadurecido, as dúvidas surgiriam sucessivamente, espontaneamente, exigindo a demonstração e então o rigor se faria necessário (POINCARÉ, 1904).

Segundo Euclides Roxo, as noções de cálculo, pela sua importância em praticamente toda área científica, seriam imprescindíveis ao homem culto. Além disso, entendia que o cálculo diferencial e integral não pertence à alta análise e sim à matemática elementar. Logo, estas noções seriam parte integrante dos conteúdos a serem trabalhados no secundário (JORNAL DO COMMERCIO, o1 mar. 1931, s/p.).

Discutia, em um dos artigos, a importância do ensino da matemática interrelacionado com outras disciplinas. A finalidade da matemática no secundário era preparar o aluno para a vida, utilizando aplicações práticas, de modo a torná-lo um cidadão para viver com dignidade em uma sociedade democrática. Era importante ensinar a matemática em perfeita interação com as outras disciplinas do curso (JORNAL DO COMMERCIO, 21 dez. 1930, s/p.).

Em suas explanações, distinguia o matemático do professor de matemática, especialmente o da escola secundária, salientando o caráter social que envolve o ensino dessa disciplina:

Ninguém contestará a um matemático normal o direito de ficar, como investigador ou estudiosos da Matemática, completamente indiferente ao valor social ou à significação humana da sua atividade. ... Desde porém que o matemático passa do papel de estudioso ou investigador ao de professor, cessa aquele direito à indiferença, pois ele passa a exercer um ofício, cujas funções são sociais, ou mesmo eminentemente sociais, e cujas obrigações são humanas (JORNAL DO COMMERCIO, 18 jan. 1931, s/p.). 
Nas obras assinadas por Euclides Roxo encontram-se diversas reflexões baseadas nos pensamentos do filósofo Henri Poincaré, os quais foram frequentemente citados. Em suas recomendações pedagógicas, defendia a apresentação gradativa das demonstrações formais aos alunos, condizentes com os estágios de desenvolvimento cognitivo em que se encontram. Propunha um ensino ministrado de forma intuitiva e gradual e, em uma fase mais adiantada, quando estivessem mais aptos à compreensão do desenvolvimento dedutivo, o professor passaria a demonstrações de modo rigoroso.

\title{
A predominância essencial do ponto de vista psicológico
}

No artigo intitulado "O ensino da matemática na escola secundária - II - Principais escopos e diretivas do movimento de reforma" publicado em 7 de dezembro de 1930, no Jornal do Commercio, enumera as principais tendências do movimento analisando, especialmente, “a predominância essencial do ponto de vista psicológico", primeira tendência a ser especificada, segundo orientação de Felix Klein. Euclides Roxo esclarecia, a respeito desse tema:

\begin{abstract}
Quer-se, com isso, significar que o ensino não pode depender unicamente da matéria a ensinar, mas deve atender, antes de tudo, ao indivíduo (subjekt), a quem se tem de educar. Um mesmo assunto será exposto a uma criança de 6 anos e a uma de 10, de modos inteiramente diferentes e muito outra será, ainda, a maneira pela qual se explicará a um adolescente. Aplicado particularmente ao ensino da Matemática, esse princípio geral nos conduz a começar sempre pela intuição viva e concreta para, só pouco a pouco, trazer ao primeiro plano os elementos lógicos, e adaptar, de preferência, o método genético ou heurístico, que permite uma penetração lenta das noções (JORNAL DO COMMERCIO, 7 dez. 1930, s/p.).
\end{abstract}

Perseverava, que o ponto de vista psicológico a que se referia dizia respeito ao ensino da matemática elementar e secundária:

\begin{abstract}
Não se trata, evidentemente de alta Matemática, exposta diante de homens, já instruídos, nos cursos públicos de faculdades e universidades; mas, se ficarmos no domínio do ensino elementar, no seu sentido mais lato, isto é, desde as primeiras noções do cálculo aritmético até as teorias da Geometria Analítica, o problema do método de ensino ... é sempre o mesmo; interessar o aluno, provocá-lo à pesquisa, dar-lhe sem cessar o sentimento (ou, se quiserem, a ilusão) de que ele mesmo é quem descobre o que se lhe ensina (JORNAL DO COMMERCIO, 7 dez. 1930, s/p.).
\end{abstract}

A reforma Francisco Campos "apropriou-se das inovações que vinham sendo implementadas, de forma paulatina, desde 1929, no colégio Pedro II” (ROCHA, 2001, p. 237). Além de se valer dos pensamentos de Felix Klein, o professor Euclides Roxo também recorreu 
das ideias pedagógicas defendidas por Henri Poincaré (1854-1912), eminente matemático francês, que proclamava ideias da corrente filosófica intuicionista da matemática.

\section{A conferência de Poincaré e sua apropriação por Euclides Roxo}

Nos artigos publicados no Jornal do Commercio, Euclides Roxo citou, em defesa de suas ideias modernizadoras, trechos da conferência realizada no Museu Pedagógico de Paris, em 1904, por Henri Poincaré, sobre "Les définitions mathématiques et l'enseignement" objetivo de melhor justificar a teoria que preconizava a necessidade de fazer preponderar o ponto de vista psicológico no ensino da matemática. Segundo Roxo, "ainda do mesmo ponto de vista, de uma maior subordinação do ensino à psicologia do estudante, a voz mais autorizada que se fez ouvir, em França, nos primórdios deste século" (JORNAL DO COMMERCIO, 7 dez. 1930, s/p.).

Nessa conferência, Poincaré tratou das definições gerais em matemática e de questões correlacionadas. Poincaré questionava o porquê da maioria das pessoas terem dificuldades para compreender a matemática, se ela é uma ciência "que só faz apelos aos princípios fundamentais da lógica”. O fato de que, no geral, as pessoas fossem incapazes de criar, segundo Poincaré, não era o que deveria preocupar o ensino, mas sim a falta de compreensão que manifestavam sobre as demonstrações que lhes eram expostas (JORNAL DO COMMERCIO, 7 dez. 1930, s/p.).

Examinar sucessivamente cada silogismo ${ }^{120}$ que compõe um teorema e constatar que está correto, não garante sua compreensão. Para Poincaré, as pessoas exigiam mais que esta constatação. Euclides Roxo transcreveu tal pensamento de Poincaré:

Presque tous sont beaucoup plus exigeants, ils voulent savoir, non seulement si tous les syllogismes d'une démonstrations sont corrects, mais pourquoi ils s'enchainent dans tel ordre, plutôt que dans tel autre. Tant qu'ils leur semblent engendres par le caprice, e non par une intelligence constamment conscience du but à atteindre, ils ne croient pas avoir compris ${ }^{121}$ (JORNAL DO COMMERCIO, 7 dez. 1930, s/p.).

Depreende-se das lições de Euclides Roxo, o qual adotou como referencial teórico os pensamentos de Henri Poincaré, para quem a maioria das pessoas tornavam-se incapazes de compreender a matemática. Posto que os teoremas se apoiam uns nos outros, inicialmente elas

\footnotetext{
${ }^{119}$ As definições matemáticas e o ensino [tradução nossa].

120 Silogismo: "No sentido lato, todo raciocínio dedutivo rigoroso e que não supõe nenhuma proposição estranha subentendida" (LALANDE, 1999, p. 1013).

${ }^{121}$ Quase todos são muito mais exigentes, eles querem saber, não somente se todos os silogismos de uma demonstração estão corretos, mas o porque deles se encadearem em tal ordem, de preferência a outra ordem. Tanto que lhes parecem produzidos pelo capricho, e não por uma inteligência constantemente consciente do objetivo a alcançar, eles não creem ter compreendido [tradução nossa] (JORNAL DO COMMERCIO, 7 de dez. 1930, s/p.). ISSN 2526-2882 
conseguiam perceber algumas evidências que, por estarem ligadas às outras por um fio tênue, poderiam não deixar vestígios no cérebro e logo caírem no esquecimento. Assim, os teoremas necessitavam de outros que jaziam esquecidos. As definições matemáticas têm vários sentidos, podendo convir e serem compreendidas por alguns e não por outros, observava Euclides Roxo. Nem sempre era culpa do professor.

Uma questão que poderia ser colocada é para que servem as definições matemáticas. Para Poincaré, necessitamos encontrar uma razão prática para a existência daquela noção matemática. Ao ensinar conceitos matemáticos o professor deveria executar uma sequência que facilitasse o aprendizado de seus alunos, enfatizava Euclides Roxo. Para tanto, considerava necessário partir de um conhecimento intuitivo para gradativamente atingir o aspecto formal que a matemática adquiriu com o tempo.

Euclides Roxo considerava que não se podia mudar a mente dos jovens e nem isso era desejável. O professor deveria se resignar à diversidade das mentes e não desejarmos querer mudá-las. Concordava também nesses aspectos com Poincaré:

Evidentemente, seria um absurdo querer obrigar os jovens a mudarem a natureza de seus espíritos: nous ne possédons pas la pierre philosophale que nous permettrait de transmuter les uns dans les antres les métaux qui nous sont confiés; tout ce que nous pouvons faire c'est de les travailler en nous accommodant à leurs propriétés (JORNAL DO COMMERCIO, 7 dez. 1930, $\mathrm{s} / \mathrm{p}.)^{122}$

Há, entre os matemáticos, lógicos como Weierstrass e intuitivos como Riemann. O mesmo ocorre com os estudantes. Uns preferem tratar os problemas pela análise matemática e outros pela geometria. Roxo ao mesmo tempo em que questionava, respondia:

Há os lógicos como Weierstrass e os intuitivos como Riemann: e é bom que assim seja, pois quem ousaria desejar que não tivesse existido Weierstrass ou que Riemann nunca houvesse escrito? Devemos, pois, resignar-nos e até regozijar-nos com a diversidade dos espíritos (JORNAL DO COMMERCIO, 7 dez. 1930, s/p.).

Abstrai-se do artigo de Roxo, todo ele amparado nas lições de Poincaré, que a lógica permite decompor cada parte da demonstração em grande número de operações elementares, todas elas corretas, o que não lhe permite ter uma visão geral de conjunto. Esta é dada pela intuição.

${ }^{122}$ Nós não possuímos a pedra filosofal que nos permitiria transmutar uns nos outros os metais que nos são confiados; tudo o que podemos fazer é trabalhá-los nos acomodando às suas propriedades [tradução nossa]. (JORNAL DO COMMERCIO, 7 de dez. 1930, s/p.).

ISSN 2526-2882 
A lógica nos indica a direção em que não encontramos obstáculo, mas não nos mostra qual caminho nos leva a atingir um determinado objetivo. É facultativo da intuição ter em mente o que queremos alcançar. Assim, se manifestou Poincaré:

Le but principal de l'enseignement mathématique est de développer certaines facultés de l'esprit et parmi elles l'intuition n'est pas la moins préciouse. C'est par elles que le monde mathématique reste en contact avec le monde réel et quand les mathématiques pures pourraient s'en passer, il faudrait toujours y avoir recours pour combler l'abime qui sépare le symbole de la réalité. Le praticien en aura toujours besoin et pour un géomètre pur il doit y avoir cent praticiens (JORNAL DO COMMERCIO, 7 dez.1930, s/p.). ${ }^{123}$

Devemos nos servir corretamente das premissas fornecidas pela intuição, para que aprendamos a raciocinar, defendia Roxo. Inicialmente, ao expor os primeiros princípios, devese evitar muitas sutilezas que podem se tornar desagradáveis e até inúteis: "Não se pode tudo demonstrar e não se pode tudo definir; e será preciso sempre recorrer à intuição" (JORNAL DO COMMERCIO, 7 dez. 1930, s/p.).

Fechando a questão, Euclides Roxo situou a feição intuicionista como base para o movimento de renovação do ensino da matemática:

\begin{abstract}
Mesmo naqueles que se terão de ser professores e aos quais se tornará indispensável um conhecimento mais profundo e rigoroso dos primeiros princípios, deve-se cultivar a intuição, sem a qual eles se fariam uma ideia falsa da ciência: aliás, não poderiam desenvolver nos seus alunos uma qualidade que eles mesmos não possuíssem.

Não quer com isso dizer que se despreze a arte de raciocinar certo; mas não faltam ocasiões para exercitar os alunos no raciocínio correto em partes de Matemática, onde não se apresentam os inconvenientes assinalados (JORNAL DO COMMERCIO, 7 dez. 1930, s/p.).
\end{abstract}

Na obra intitulada "A matemática na educação secundária” publicada pela Companhia Editora Nacional em 1937, Euclides Roxo defendeu que a intuição é uma faculdade tão valiosa quanto o raciocínio, devendo ser desenvolvida e educada no ensino de matemática. Novamente, fez referências a trechos da conferência de Poincaré, "Les définitions matématiques" quando o filósofo questiona o motivo pelo qual tantas pessoas se recusam a compreender a matemática. Assim se manifestou Euclides Roxo:

Poincaré reconhece, pois que não basta apresentar aos alunos a luz clara do raciocínio lógico, para que eles vejam a verdade matemática. Continuam

\footnotetext{
123 O objetivo principal do ensino matemático é desenvolver algumas faculdades do espírito e entre elas a intuição não é a menos preciosa. É por ela que o mundo matemático permanece em contato com o mundo real e quando a matemática pura puder passar sem ela, é preciso sempre ter recursos para encher o abismo que separa o símbolo da realidade. O prático terá sempre necessidade dela e para um geômetra puro deve haver cem práticos [tradução nossa].
} 
'cegos'. No ensino da matemática, mesmo aquela fase elevada, de cujos exames Poincaré tinha experiência, nada adianta a simples apresentação de um encadeamento lógico das proposições.

'Compreender' não tem o mesmo sentido para todos. Embora sem saber o que lhes falta, a maioria não se contenta com a correção dos silogismos de uma demonstração, que lhes parecem fruto de um mero capricho, pois que não se tornam conscientes do fim que se tem em vista.

O fio com que se prendem as evidências, que se lhes apresentam, é demasiado tênue para que o vejam constantemente. (...) Culpa do professor? Preguiça do aluno? Como combatê-la? Aliás, combater o quê? [grifos do autor], (ROXO, 1937. p. 64-65).

Além disso, Euclides Roxo ponderava que, mesmo entre os adultos, o raciocínio puramente lógico, nem sempre é aceito prontamente. Considerava que a exagerada preocupação com o rigor é o maior obstáculo para uma adoção da intuição como base para o ensino da matemática.

A essa alusão, Euclides Roxo acrescentou os seguintes dizeres de Poincaré, de modo a tornar incontestável a sua colocação: "É inútil ressaltar quanto seria funesta ao ensino e prejudicial ao desenvolvimento dos espíritos; quanto seria ressicante para os pesquisadores, cuja originalidade estancaria prontamente...” (ROXO, 1937, p.76).

Euclides Roxo discutiu ainda a utilização da base de conhecimentos intuitivos anteriormente adquiridos. E afirmou: "Quando as crianças começam a estudar matemática já formaram muitas intuições em relação ao espaço e ao movimento”. Essa afirmação suscitou as seguintes questões: "Qual a atitude do educador perante tais intuições? Devem ser aceitas sem discussão e utilizadas como postulados devem ser ignoradas ou devem ser discutidas?” (ROXO,1937, p.72).

Por considerar que não é a apresentação de um raciocínio estritamente matemático que pode educar uma criança, Euclides Roxo sustentava que ao iniciar um estudo, o professor deveria deixar que o aluno utilizasse suas próprias intuições, sendo assim mais fácil, posteriormente, moldar-lhe o pensamento em um tipo mais formal. A capacidade do aluno para a abstração e a dedução formal iria aumentando lentamente, desde que não se tentasse forçá-la. Convinha, pois, aceitar uma ideia grosseira e pouco precisa que os alunos já poderiam ter dos conceitos.

Assim, Euclides Roxo concluiu que, o ensino da matemática não deveria ficar limitado ao treino da capacidade de raciocínio dedutivo, mas a uma formação estrutural, em que a capacidade de intuição era das mais relevantes.

\section{Conclusão}

A Reforma Francisco Campos, no que se refere ao ensino da Matemática, acatou quase que integralmente as propostas modernizadoras de Euclides Roxo, até então colocadas em 
prática no Colégio Pedro II. A partir da reforma então, passamos a ter apenas a disciplina matemática, ao invés da clássica separação em três ramos (aritmética, álgebra e geometria).

Naquele período de implantação da reforma da educação brasileira, o professor Euclides Roxo teve importante participação, quando buscou no movimento internacional sua modernização por meio dos princípios norteadores de sua proposta. Aquela participação, tanto na reforma de ensino ocorrida no Colégio Pedro II e mais tarde, na reforma Francisco Campos, foi consequência de suas veementes defesas de seu pensamento no Jornal do Commercio e em seu livro, revelando como a educação recebia forte influência das relações políticas, sendo indissociável um movimento do outro. Não obstante, deixou evidenciado que no ensino da matemática essa questão política raramente é discutida, não se explicando como ocorre a inclusão ou exclusão de um determinado conteúdo matemático. Tal fato, não pode ser explicado senão por meio de uma análise histórica.

Euclides Roxo, ao defender a predominância essencial do ponto de vista psicológico, como importante ferramenta no auxílio da pedagogia escolar, entrou em choque com a posição assumida pelos professores tradicionais da disciplina, que se importavam apenas em "ensinar a matemática por um método exclusivamente dedutivo, fazendo derivar, logicamente, todas as suas proposições de uma série de axiomas previamente estabelecidos", sem levar em consideração fatores pedagógicos e psicológicos próprios dos adolescentes (DUARTE, 2002, p. 121).

Assim, evocando primordialmente as ideias de Henri Poincaré, filósofo intuicionista, Roxo justificou seu pensamento perante a sociedade da época. Acreditava na contribuição que prestava para o ensino moderno da matemática, o que acabou por prevalecer mesmo que por força ou obra de uma reforma imposta para todo o país.

O movimento renovador do ensino destacou a importância da intuição na construção do conhecimento, de modo a motivar o aluno a um aprendizado mais eficiente, contribuindo não só para o desenvolvimento de atividades mais atraentes e inovadoras na escola, como também para o aumento da demanda de estudantes interessados em dar continuidade ao estudo dessa ciência, no curso superior. Portanto, com a adoção de alguns aspectos presentes e próprios da corrente filosófica do Intuicionismo, a par com as reformulações de conceitos até então empregados no ensino tradicional, surgiram também discussões generalizadas no seio da sociedade brasileira, promovendo uma reflexão acerca de um modelo até então aceito, sem maiores questionamentos.

Euclides Roxo procurou, na conferência de Poincaré, "Les définitions mathématiques" amparo para suas proposições. Não fez nenhum reparo aos pensamentos de Poincaré, adotando-os integralmente, utilizando-se da autoridade desse matemático para 
atestar o desinteresse dos alunos por essa ciência, aproveitando para mostrar a ineficiência do excesso de rigor dos mestres.

Assim, nasce o desafio de responder a duas questões que afloram naturalmente: quais as dinâmicas que envolvem a relação entre a educação matemática e a filosofia da matemática? Como os aspectos intuitivo e lógico foram considerados na nova matemática escolar proposta no Brasil, a partir de 1931?

\section{Referências}

APER - Arquivo Pessoal Euclides Roxo. São Paulo: Grupo de Pesquisa em História da Educação Matemática (GHEMAT).

ATAS - Doc. 1, Imagem 173. São Paulo: Grupo de Pesquisa em História da Educação Matemática (GHEMAT).

BRUTER, C. Comprende les mathématiques: les 10 notions fondamentales. França, Odile Jacob, 1996.

CHARTIER, R. O mundo como representação. In: Estudos avançados. 11(5). IEA-USP. São Paulo, 1991.

. A história cultural: entre práticas e representações. Lisboa: Difel, 1990.

DUARTE, A. R. S. Henri Poincaré e Euclides Roxo: subsídios para a história das relações entre filosofia da matemática e educação matemática. São Paulo, 2002. Dissertação (Mestrado em Educação Matemática) - Pontifícia Universidade Católica de São Paulo, PUC/SP, 2002.

. História da educação matemática: trajetos investigativos. Ano 3, n. 2. HISTEMAT, 2017. Disponível em <https://repositorio.ufsc.br/bitstream/handle/123456789/189567/Duarte>. Acesso em 06 jan. 2018.

LALANDE, A. Vocabulário técnico e crítico de filosofia. 3 ed. São Paulo: Martins Fontes, 1999.

MACHADO, R. C. G. Uma análise dos exames de admissão ao secundário (1930 1970): subsídios para a história da educação matemática no Brasil. São Paulo, 2002. Dissertação (Mestrado em Educação Matemática) - Pontifícia Universidade Católica de São Paulo, PUC/SP, 2002.

PINTO, N. B. Desafios e contribuições da história cultural para os educadores matemáticos. In: ENS, R. T. ; BEHERENS, M.A.. (Org.). Formação do professor: profissionalização, pesquisa e cultura escolar. 1ed.Curitiba: Champagnat, 2010, v. 1, p. 225-238. 
POINCARÉ, H. Les définitions générales en mathématiques. L'Enseignement Mathématique, $6^{\circ}$ année, 1904. Disponível em: <http://henripoincarepapers.univlorraine.fr/bibliohp/?\&a $=$ on\&ln=Poincar\%C3\%A9\&fn=Henri\&action=go\&page=5) >. Acesso em 10 jul. 2017.

ROCHA, J. L. A matemática do curso secundário na reforma Francisco Campos. Rio de Janeiro, 2001. Dissertação (Mestrado em Matemática). Pontifícia Universidade Católica do Rio de Janeiro. Rio de Janeiro, 2001.

ROXO, E. O ensino da matemática na escola secundária - I - O moderno movimento de reforma e seus precursores. Jornal do Commercio, Rio de Janeiro, 30 nov. 1930. . O ensino da matemática na escola secundária - II - Principais escopos e diretivas do movimento de reforma. Jornal do Commercio, Rio de Janeiro, o7 dez. 1930. . O ensino da matemática na escola secundária - III - Principais escopos e diretivas do movimento de reforma - 1. Predominância essencial do ponto de vista psicológico - Conexão entre as diversas partes da matemática. Jornal do Commercio, Rio de Janeiro, 14 dez. 1930.

. O ensino da matemática na escola secundária - IV - Principais escopos e diretivas do movimento de reforma - 2. Subordinação da escolha da matéria a ensinar às aplicações de matemática ao conjunto de outras disciplinas. Jornal do Commercio, Rio de Janeiro, 21 dez. 1930.

. O ensino da matemática na escola secundária - VIII - Principais escopos e diretivas do movimento de reforma - 3. Subordinação do ensino de matemática à finalidade da escola moderna. Jornal do Commercio, Rio de Janeiro, 18 jan. 1931.

. O ensino da matemática na escola secundária - XIII - Principais escopos e diretivas do movimento de reforma - Inclusão das noções de cálculo infinitesimal. Jornal do Commercio, Rio de Janeiro, $1^{\circ}$ mar.1931.

. A matemática na educação secundária. São Paulo: Cia. Editora Nacional, 1937.

TAVARES, J. C. A congregação do Colégio Pedro II e os debates sobre o ensino de matemática. São Paulo, 2002. Dissertação (Mestrado em Educação Matemática). Programa de Estudos Pós-Graduados em Educação Matemática - Pontifícia Universidade Católica de São Paulo, PUC/SP, 2002.

VALENTE, W. R. Uma história da matemática escolar no Brasil (1730 - 1930). São Paulo: Annablume, 1999.

. O conceito de função: política e educação matemática no Brasil dos anos 1930 - 1945. VII ENEM (Encontro Nacional de Educação Matemática). Anais... Rio de Janeiro, 2001.

. (Org.). O nascimento da matemática do ginásio. São Paulo: Annablume, 2004.

ISSN 2526-2882 
WERNECK, A. P. T. Euclides Roxo e a reforma Francisco Campos: a gênese do primeiro programa de ensino de matemática brasileiro. São Paulo, 2003. Dissertação (Mestrado em Educação Matemática). Programa de Estudos Pós-Graduados em Educação Matemática - Pontifícia Universidade Católica de São Paulo, PUC/SP, 2003.

\section{Biografia Resumida}

Aparecida Rodrigues Silva Duarte: Bacharel e licenciada em Matemática pela Pontifícia Universidade Católica de São Paulo (PUC/SP); mestre e doutora em Educação Matemática pela Pontifícia Universidade Católica de São Paulo (PUC/SP). Docente do Curso de Pós-graduação em Educação da Universidade do Vale do Sapucaí/MG (UNIVÁS/MG). Integrante do Grupo de Pesquisa de História da Educação Matemática (GHEMAT) e Grupo de Estudos e Pesquisa em História da Educação e Tecnologias na Educação - UNIVÁS (GPHET).

Link Lattes: http://Link Lattes.cnpq.br/8300934292118606 e-mail: aparecida.duarte6@gmail.com 